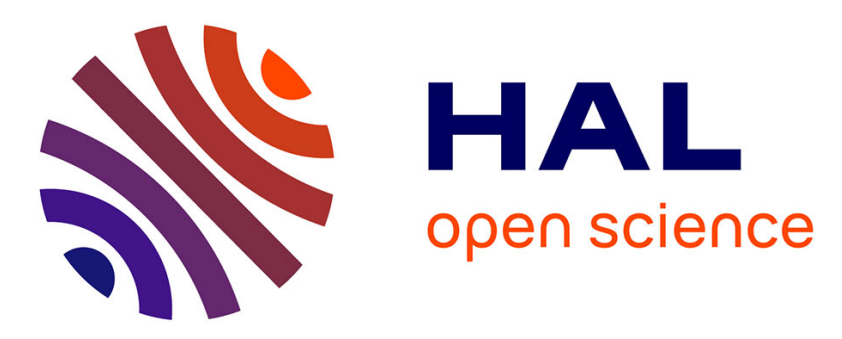

\title{
Processing-induced-transformations (PITs) during direct compression: impact of compression speeds on phase transition of caffeine
}

\author{
Audrey Juban, Stephanie Briancon, François Puel
}

\section{To cite this version:}

Audrey Juban, Stephanie Briancon, François Puel. Processing-induced-transformations (PITs) during direct compression: impact of compression speeds on phase transition of caffeine. Drug Development and Industrial Pharmacy, 2016, 42 (11), pp.1857 - 1864. 10.1080/03639045.2016.1179753 . hal01398336

\section{HAL Id: hal-01398336 \\ https://hal.science/hal-01398336}

Submitted on 5 Jan 2017

HAL is a multi-disciplinary open access archive for the deposit and dissemination of scientific research documents, whether they are published or not. The documents may come from teaching and research institutions in France or abroad, or from public or private research centers.
L'archive ouverte pluridisciplinaire HAL, est destinée au dépôt et à la diffusion de documents scientifiques de niveau recherche, publiés ou non, émanant des établissements d'enseignement et de recherche français ou étrangers, des laboratoires publics ou privés. 
This Accepted author version posted online: 24 Apr 2016. Published online: 10 May 2016

To cite this article: Audrey Juban, Stephanie Briancon \& François Puel (2016) Processinginducedtransformations (PITs) during direct compression: impact of compression speeds on phase transition of caffeine, Drug Development and Industrial Pharmacy, 42:11, 1857-1864, DOI: $10.1080 / 03639045.2016 .1179753$

\title{
Title: Processing-induced-transformations (PITs) during direct compression: Impact of compression speeds on phase transition of caffeine.
}

\section{Author names and affiliations:}

Audrey JUBANª, Stéphanie BRIANCON ${ }^{a}$, François PUEL ${ }^{a, b}$.

a Univ Lyon, Universite Lyon 1, CNRS, UMR5007, LAGEP, 43 bd du 11 Novembre 1918, F-69622 LYON, France

${ }^{b}$ LGPM, Laboratoire de Génie des Procédés et Matériaux, CentraleSupélec, Université Paris-Saclay, Grande Voie des Vignes, 92295 Châtenay-Malabry, France

15 Corresponding author: Prof. F. Puel, +33 (0)1 411311 09, francois.puel@centralesupelec.fr

\begin{abstract}
For pharmaceutical industry, understanding solid phase transition of the active pharmaceutical ingredient (API) induced by the manufacturing process is a key issue. Caffeine was chosen as a model API since it exhibits a polymorphic transformation during tableting. This study investigated the impact of the compression speed on the phase transition of anhydrous Form I (CFI) into Form II. Tablets were made from pure $\mathrm{CFI}$ and binary mixtures of $\mathrm{CFI} /$ microcrystalline cellulose, with an electric press well instrumented at three different compression speeds $\left(50,500\right.$ and $\left.4500 \mathrm{~mm} \cdot \mathrm{min}^{-1}\right)$. For each velocity of the mobile punch studied, tablets made from three compression pressures (50, 100 and $200 \mathrm{MPa}$ ) were analysed. The 25 determination of the CFI transition degree was performed using a Differential Scanning Calorimetry (DSC). The CFI transition degree was monitored during three months in order to obtain the transformation profile of the API in tablets and in uncompressed powder. The modelling of the profile with a stretched
\end{abstract}


exponential kinetic law (Johnson-Mehl-Avrami model) was used for the identification of the transition mechanism. The direct compression process triggered the polymorphic transformation in tablet when a sufficient compression pressure is applied. The velocity of the punch did not impact the transition degree just after compression nor the transformation profile. The transition mechanism remained driven by nucleation whatever the operating conditions. Consequently, the punch velocity is not a decisive process parameter for avoiding such phase transition in tableting. As already observed, the compression pressure did not influence the transition, whatever, the compression speed and the velocity.

Keywords : Direct compression ; Tableting, Polymorphic transformation, Processing induced transition (PITs), Process parameters, Caffeine

\section{Introduction}

40 For pharmaceutical industry, processing-induced-transformations (PITs) in drug products manufacturing are of great importance. Several authors have started to work on these transformations ${ }^{1-4}$. Solid-state transitions that may occur during manufacturing processes can affect the quality of the final dosage form ${ }^{5}$. Even now, manufacturers have no control over these phenomena. A recent theoretical approach of the PITs assumes that each step of a process can generate a stress (thermal, mechanical or chemical) which could cause a modification in the thermodynamic equilibrium of the system and lead to a phase transformation of the product ${ }^{6-7}$.

Nowadays, tablets are the most popular pharmaceutical dosage forms in production ${ }^{8-9}$. In the past few years, the use of direct compression has rapidly increased ${ }^{10}$ due to its economic interest and its process which avoids the steps of wet granulation and drying processes. In the pharmaceutical field, it is well

50 known that active pharmaceutical ingredients (APIs) and excipients may exist under different crystalline forms depending on the treatment that they received ${ }^{11,12}$. For solid dosage form development, it is recommended to use the stable form of the API, as the starting material ${ }^{13}$. However, as each polymorphic form has its own physico-chemical properties (such as solubility, dissolution rate, and bioavailability), metastable forms may be used in pharmaceutical development because of the desired properties for the

55 final product. Many parameters in the manufacturing process itself could have an impact on these phase 
transitions. In the literature, several authors have observed polymorphic transformations occurring during the compression process ${ }^{14-18}$.

In this work, caffeine $\left(\mathrm{C}_{8} \mathrm{H}_{10} \mathrm{~N}_{4} \mathrm{O}_{2}\right)$ was used as a model API. Two polymorphic forms of caffeine are known and called Form I and Form II. The commercial anhydrous caffeine Form II is stable at room temperature until $145^{\circ} \mathrm{C}$ and the Form $\mathrm{I}$ is stable at ambient pressure from the transition temperature $\left(145^{\circ} \mathrm{C}\right)$ until its melting point $236{ }^{\circ} \mathrm{C}^{19}$. This common molecule, which presents simple enantiotropic behaviour and a reversible transformation at solid state, is well known for polymorphic studies ${ }^{18,20-22}$.

In a previous work ${ }^{4}$, three parameters that could impact the phase transition of the caffeine Form I (CFI) into Form II (CFII) have been analysed: nature of the diluent, dilution of the API and compression pressure.

65 The two first formulation parameters have an impact on the CFI transition degree. By contrast, for the two binary systems studied, the authors have shown that the transition degree induced by the compression was not dependent on $f$ the compression pressure.

This study, complementary to this previous work, focused on the evaluation of the impact of another process parameter on the phase transition of caffeine Form I: the compression speed (i.e. velocity of the

70 mobile punch) during tableting. Indeed, it is well known that compression speed, applied during tableting, can have significant effects on the compaction properties of pharmaceutical powder $r^{8,23-26}$. Garr and Rubinstein ${ }^{23}$ have showed that the capping pressures decrease with increasing speed of compression. Moreover, Larhrib et al. ${ }^{25}$ display an increase in the mean yield pressure with the compression speed. Consequently, the compression speed during tableting may also have an impact on the polymorphic 75 transition of the caffeine Form I into Form II. Up to our knowledge, this point was not yet investigated in the literature. In this study, tablets were made at three different compression speeds. During tableting, the compression speed was constant until the maximum compression pressure defined was reached. The control of this parameter was possible with the compression technique used (electric press), which was not the case in the previous study (compression driven by force). In addition, for each velocity of the mobile punch studied, tablets made from three compression pressures were analysed. The determination of the solid-solid phase transition of caffeine Form I was performed by thermal analysis. 


\section{Material and methods}

\section{Materials}

The caffeine Form I (CFI) was used as a model API. It was obtained by using the same method as described by Juban et al. ${ }^{4}$. In order to ensure that the particles exhibit a $100 \%$ polymorphic purity (Form I), a Differential Scanning Calorimetry (DSC) analysis was performed for each batch of CFI (results not shown). Microcrystalline cellulose (MCC), Avicel ${ }^{\circledR} \mathrm{PH}-102$, was obtained from FMC Biopolymer.

90 The particle size distribution for these two materials was measured with a Mastersizer ${ }^{\circledR} 3000$ using an AeroS dry dispersion unit (Malvern Instruments, U.K.). The Fraunhofer model was selected in order to transform the dynamic light scattering measurements in a particle size distribution. The resulting volume density function was averaged. The calculation of the different standard percentile ( $D_{v} 10, D_{v} 50$ and $\left.D_{v} 90\right)$ was performed following the British standard BS2955.1993. Measurements were performed in triplicate

95 on each powder. Their values with their standard deviations are listed in Table 1.

Table.1: Particle size distribution parameters of CFI and MCC $(n=3)$

\begin{tabular}{cccc}
\hline Powders & $\begin{array}{c}\mathbf{D}_{\mathbf{v}} \mathbf{1 0}{ }^{\mathrm{a}} \\
(\mu \mathrm{m})\end{array}$ & $\begin{array}{c}\mathbf{D}_{\mathbf{v}} \mathbf{5 0} \\
(\mu \mathrm{m})\end{array}$ & $\begin{array}{c}\mathbf{D}_{\mathbf{v}} \mathbf{9 0}{ }^{\mathrm{a}} \\
(\mu \mathrm{m})\end{array}$ \\
\hline $\mathrm{CFI}$ & $19.7 \pm 0.7$ & $67.8 \pm 2.1$ & $160.5 \pm 3.5$ \\
$\mathrm{MCC}$ & $28.3 \pm 0.1$ & $119.0 \pm 0.0$ & $268.7 \pm 1.2$ \\
\hline
\end{tabular}

${ }^{\mathrm{a}}$ Average calculated from 3 measurements

\section{Tablets preparation}

Cylindrical tablets were prepared with a binary mixture of anhydrous caffeine Form I (a day after its manufacture) and MCC as a diluent. Diluent was mixed in various proportions with caffeine content of 78 and90 wt\% of CFI. The blending was performed with a tridimensional mixer (Turbula ${ }^{\circledR} \mathrm{T} 2 \mathrm{~F}$ ) at a rotational rate of $49 \mathrm{rpm}$ (for 10 minutes). A series of pure CFI tablets (100 wt\% of CFI) was also made. All compacts were made at constant mass (about $150 \mathrm{mg}$ ) by using a tensile test system (ElectroPuls ${ }^{\mathrm{TM}}$ E10000, Instron ${ }^{\circ}$, Élancourt, France), and its data acquisition software (WaveMatrix ${ }^{\mathrm{TM}}$, Instron ${ }^{\circ}$ ). A sensor of $10 \mathrm{kN}$ was used.

105 Compressions were performed with an electric press. The compression is driven by displacement until reaching the required force. This technology allows obtaining a constant compression speed. The acquisition of the position of the punch and the pressure is made with a frequency of $10 \mathrm{~Hz}$. The mean relative deviation of the compression speed during tableting is of $5 \%$. Specific tools with flat-punches 6.50 
$\mathrm{mm}$ of diameter, and die set, were fitted on the device. Compression was made by the upper punch. The 110 compression forces were measured with the sensor located on the upper punch. In this work, tablets were produced without lubricant. Three different compression speeds were studied: 50, 500, $4500 \mathrm{~mm} \cdot \mathrm{min}^{-1}$ for three different compression forces $(1.66 \mathrm{kN}, 3.32 \mathrm{kN}, 6.64 \mathrm{kN})$ corresponding at 50 MPa, $100 \mathrm{MPa}$ and $200 \mathrm{MPa}$ in compression pressure, respectively. The tablet weight and thickness (shown in Table 2) were measured just after compression according to the European Pharmacopoeia method section 2.09.05 ${ }^{27}$.

115 The storage was made at room temperature during three months.

Table.2: Tablet characteristics

\begin{tabular}{|c|c|c|c|c|c|c|c|c|c|}
\hline Diluent & Composition & $\begin{array}{c}\text { Compression } \\
\text { speed (v) }\end{array}$ & $\begin{array}{c}\text { Compression } \\
\text { load }^{\text {b }}(\mathrm{P})\end{array}$ & $\begin{array}{c}\text { Tablet } \\
\text { weight }^{b}(w)\end{array}$ & $\begin{array}{c}\text { Tablet } \\
\text { thickness }{ }^{\mathrm{b}}(\mathrm{t})\end{array}$ & $\begin{array}{c}\text { Tablet } \\
\text { diameter }^{\mathrm{b}} \\
\text { (D) }\end{array}$ & $\begin{array}{l}\text { Particle } \\
\text { density } \\
\left.\text { ( } \rho_{\text {blend }}\right)\end{array}$ & $\begin{array}{c}\text { Tablet } \\
\text { Density }^{\mathrm{b}} \text { (d) }\end{array}$ & $\begin{array}{c}\text { Tablet } \\
\text { Porosity }{ }^{\mathrm{b}}(\varepsilon)\end{array}$ \\
\hline$(-)$ & (wt\% CFI) & $\left(\mathrm{mm} \cdot \mathrm{min}^{-1}\right)$ & (MPa) & (mg) & $(\mathrm{mm})$ & $(\mathrm{mm})$ & $\left(\mathrm{g} . \mathrm{cm}^{-3}\right)$ & $\left(\mathrm{g} . \mathrm{cm}^{-3}\right)$ & (\%) \\
\hline & & & $198.8 \pm 0.2$ & $148.1 \pm 1.3$ & $3.35 \pm 0.04$ & $6.51 \pm 0.00$ & & $1.326 \pm 0.010$ & $8.30 \pm 0.69$ \\
\hline & & 50 & $99.2 \pm 0.3$ & $147.8 \pm 1.4$ & $3.55 \pm 0.03$ & $6.52 \pm 0.01$ & & $1.251 \pm 0.005$ & $13.49 \pm 0.33$ \\
\hline & & & $49.5 \pm 0.2$ & $146.5 \pm 2.7$ & $3.77 \pm 0.06$ & $6.52 \pm 0.01$ & & $1.168 \pm 0.003$ & $19.19 \pm 0.22$ \\
\hline & & & $195.2 \pm 0.6$ & $146.1 \pm 2.0$ & $3.31 \pm 0.05$ & $6.52 \pm 0.01$ & & $1.321 \pm 0.006$ & $8.64 \pm 0.42$ \\
\hline & 100 & 500 & $95.9 \pm 0.5$ & $146.0 \pm 1.7$ & $3.50 \pm 0.04$ & $6.52 \pm 0.01$ & $1.446^{\mathrm{a}}$ & $1.250 \pm 0.008$ & $13.55 \pm 0.54$ \\
\hline & & & $47.6 \pm 1.0$ & $146.5 \pm 1.5$ & $3.75 \pm 0.04$ & $6.52 \pm 0.01$ & & $1.170 \pm 0.005$ & $19.07 \pm 0.36$ \\
\hline & & & $201.6 \pm 0.8$ & $148.3 \pm 2.3$ & $3.37 \pm 0.06$ & $6.51 \pm 0.00$ & & $1.315 \pm 0.008$ & $9.05 \pm 0.544$ \\
\hline & & 4500 & $104.1 \pm 0.9$ & $147.2 \pm 1.8$ & $3.50 \pm 0.05$ & $6.52 \pm 0.01$ & & $1.260 \pm 0.004$ & $12.84 \pm 0.30$ \\
\hline & & & $48.6 \pm 0.6$ & $148.2 \pm 1.1$ & $3.79 \pm 0.03$ & $6.53 \pm 0.00$ & & $1.175 \pm 0.002$ & $18.76 \pm 0.15$ \\
\hline \multirow{18}{*}{ MCC } & \multirow{9}{*}{90} & & $198.5 \pm 0.3$ & $149.0 \pm 1.0$ & $3.36 \pm 0.03$ & $6.52 \pm 0.01$ & \multirow{9}{*}{$1.457^{c}$} & $1.326 \pm 0.011$ & $9.00 \pm 0.77$ \\
\hline & & 50 & $99.1 \pm 0.2$ & $146.8 \pm 3.0$ & $3.56 \pm 0.07$ & $6.52 \pm 0.01$ & & $1.234 \pm 0.003$ & $15.29 \pm 0.23$ \\
\hline & & & $49.5 \pm 0.1$ & $148.1 \pm 1.4$ & $3.90 \pm 0.03$ & $6.52 \pm 0.00$ & & $1.137 \pm 0.002$ & $21.94 \pm 0.15$ \\
\hline & & & $193.7 \pm 0.8$ & $147.5 \pm 1.4$ & $3.34 \pm 0.05$ & $6.52 \pm 0.00$ & & $1.322 \pm 0.010$ & $9.28 \pm 0.67$ \\
\hline & & 500 & $96.2 \pm 0.5$ & $148.7 \pm 1.8$ & $3.60 \pm 0.04$ & $6.52 \pm 0.01$ & & $1.236 \pm 0.009$ & $15.16 \pm 0.64$ \\
\hline & & & $47.9 \pm 0.3$ & $148.6 \pm 2.1$ & $3.88 \pm 0.06$ & $6.53 \pm 0.01$ & & $1.147 \pm 0.003$ & $21.30 \pm 0.18$ \\
\hline & & \multirow{3}{*}{4500} & $198.5 \pm 0.6$ & $147.5 \pm 2.3$ & $3.28 \pm 0.04$ & $6.52 \pm 0.00$ & & $1.350 \pm 0.024$ & $7.31 \pm 1.62$ \\
\hline & & & $104.0 \pm 1.3$ & $145.9 \pm 0.9$ & $3.51 \pm 0.02$ & $6.52 \pm 0.01$ & & $1.248 \pm 0.010$ & $14.31 \pm 0.71$ \\
\hline & & & $50.4 \pm 0.6$ & $147.4 \pm 2.3$ & $3.84 \pm 0.04$ & $6.51 \pm 0.00$ & & $1.151 \pm 0.023$ & $21.02 \pm 1.60$ \\
\hline & \multirow{9}{*}{78} & & $200.2 \pm 0.2$ & $148.6 \pm 1.8$ & $3.34 \pm 0.03$ & $6.52 \pm 0.00$ & \multirow{9}{*}{$1.470^{c}$} & $1.331 \pm 0.004$ & $9.44 \pm 0.25$ \\
\hline & & 50 & $100.4 \pm 0.4$ & $148.4 \pm 0.6$ & $3.61 \pm 0.02$ & $6.52 \pm 0.01$ & & $1.233 \pm 0.004$ & $16.11 \pm 0.26$ \\
\hline & & & $50.4 \pm 0.4$ & $149.3 \pm 1.0$ & $4.01 \pm 0.04$ & $6.52 \pm 0.01$ & & $1.114 \pm 0.005$ & $24.19 \pm 0.32$ \\
\hline & & & $200 \pm 1.1$ & $149.1 \pm 2.0$ & $3.37 \pm 0.05$ & $6.51 \pm 0.01$ & & $1.326 \pm 0.016$ & $9.83 \pm 1.10$ \\
\hline & & 500 & $99.6 \pm 0.4$ & $148.5 \pm 2.3$ & $3.63 \pm 0.06$ & $6.52 \pm 0.01$ & & $1.227 \pm 0.004$ & $16.54 \pm 0.27$ \\
\hline & & & $49.4 \pm 0.5$ & $147.6 \pm 2.2$ & $3.98 \pm 0.06$ & $6.52 \pm 0.01$ & & $1.113 \pm 0.004$ & $24.29 \pm 0.24$ \\
\hline & & \multirow{3}{*}{4500} & $200.4 \pm 0.8$ & $148.9 \pm 1.5$ & $3.35 \pm 0.03$ & $6.51 \pm 0.01$ & & $1.332 \pm 0.009$ & $9.39 \pm 0.61$ \\
\hline & & & $100.7 \pm 0.2$ & $149.0 \pm 1.7$ & $3.62 \pm 0.04$ & $6.52 \pm 0.01$ & & $1.233 \pm 0.003$ & $16.12 \pm 0.23$ \\
\hline & & & $50.0 \pm 0.9$ & $148.2 \pm 2.3$ & $3.97 \pm 0.06$ & $6.52 \pm 0.01$ & & $1.120 \pm 0.002$ & $23.82 \pm 0.15$ \\
\hline
\end{tabular}

\footnotetext{
${ }^{\mathrm{a}}$ Measured by helium pycnometry Hubert (2012) $\quad{ }^{\mathrm{b}}$ Average calculated from 10 tablets

${ }^{\mathrm{C}}$ Calculated from true density of pure MCC by using a mixing rules $\left(\rho_{\mathrm{MCC}}=1.561 \mathrm{~g} . \mathrm{cm}^{-3}\right)$
} 
The Differential Scanning Calorimetry (DSC) device used for the calorimetric measurements was a Q200 from TA Instruments. Calibration was performed with indium. Aluminum crucibles with perforated caps were used and the heating rate was $10^{\circ} \mathrm{C} \cdot \mathrm{min}^{-1}$ from $20^{\circ} \mathrm{C}$ to $270^{\circ} \mathrm{C}$ under a nitrogen purge of $50 \mathrm{~mL} / \mathrm{min}$. MCC releases water when heated above $40{ }^{\circ} \mathrm{C}$. Thus and to avoid an increase of pressure in the crucible, a 125 hole was made in the lids for DSC measurements. This method ensured a good reliability of the experiments. Analyses were made in triplicate. DSC takes into account a macroscopic fraction (about 10 $\mathrm{mg}$ ) of the tablet and was applied in order to estimate the transition degree in the core of tablet. For the studies of CFI transition degree, a kinetic analysis has been performed for each mixture (uncompressed powders and tablets), at the following specific times: $2,15,30,45,60$ and 90 days after tablets fabrication.

130 Uncompressed powders were considered as the references, in order to investigate the tableting impact by comparing the transition kinetic profiles between tablets and uncompressed powders.

Concerning crucibles preparation, two methods were used depending on the type of the sample: powder or tablet. For powders, around $10 \mathrm{mg}$ of sample was put in the crucible. For a correct and reproducible DSC analysis, the bottom of each crucible must be completely covered by the sample. Indeed, this method

135 allows ensuring a homogeneous temperature distribution throughout the sample. Consequently, a special tool was designed for these thermal analyses: a flat punch with a diameter slightly lower than the crucible one. This tool allow to pack the powder on the bottom of the cap. For tablet a similar method was used. As describe by Fig.1, the core of tablet was cut by using a cutter blade. Then, this part was put in the crucible, without grinding step, and flattened by using the special tool in order to entirely cover the bottom

140 of the cap. These methods of preparation, without grinding step, allow ensuring that no mechanical stress was applied on samples. Consequently, the crucibles preparation did not induce the polymorphic transformation of the caffeine Form $\mathrm{I}$.

As described by Juban et $a I^{4}$, the transition degree $(\tau)$ of the caffeine Form I into Form II was obtained with Eq. 1:

$145 \tau=\frac{\Delta_{\text {trans }} H_{(I I \rightarrow I)} \text { of the sample }}{\Delta_{\text {trans }}{ }_{(I I \rightarrow I)} \text { of pure form II }} \cdot \frac{\Delta_{\text {fus }} H_{(I)} \text { of pure form } I}{\Delta_{\text {fus }^{H}}{ }_{(I)} \text { of the sample }}$

The experimental validation of this method (results shown in Juban et $a . .^{4}$ ) was performed, for each composition studied, in order to confirm the Expression (1). 


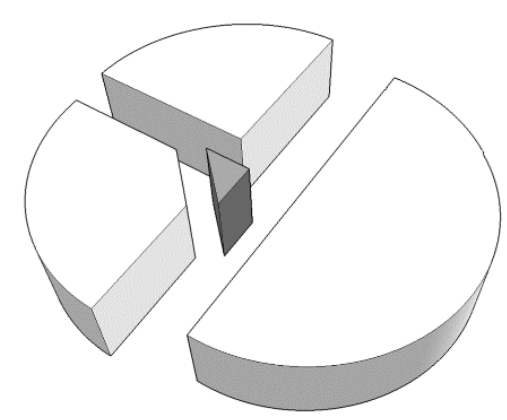

150

Fig.1: Sample fraction (black part) of tablet for DSC Analysis.

\section{Statistical analysis}

In this work, statistical analyses were performed using the R software (The R foundation) with a threshold 155 of $5 \%$ corresponding to the alpha risk. As all data were not normally distributed and variances were not equal, consequently, data could not be normalized, a non-parametric Kruskal-Wallis test was performed. In order to determine significant differences between two parameters, a multiple comparison post hoc test (kruskalmc) was conducted.

\section{Results}

\section{Evolution of the CFI transition degree $(\tau)$ in uncompressed powders}

During three months, a kinetic study was conducted in order to observe the evolution over time of the CFI transition degree $(\tau)$ in uncompressed powders (see Fig.2). Each symbol represents one of the three compositions studied: pure CFI and binary mixtures of CFI/MCC: 90 and 78 wt\% of CFI.

165 Two transition profiles were observed: one for pure CFI and another one for powder mixtures. Uncompressed powder of pure caffeine Form I showed a first quick transition stage over the first 15 days until reaching a plateau (about $30 \%$ ) from the fifteenth day. However, for the two binary mixtures, this quick transition stage has lasted 60 days. After that, a plateau value of about $55 \%$ was reached. For the transition degree values, the difference observed between the two mixtures was not significant. 


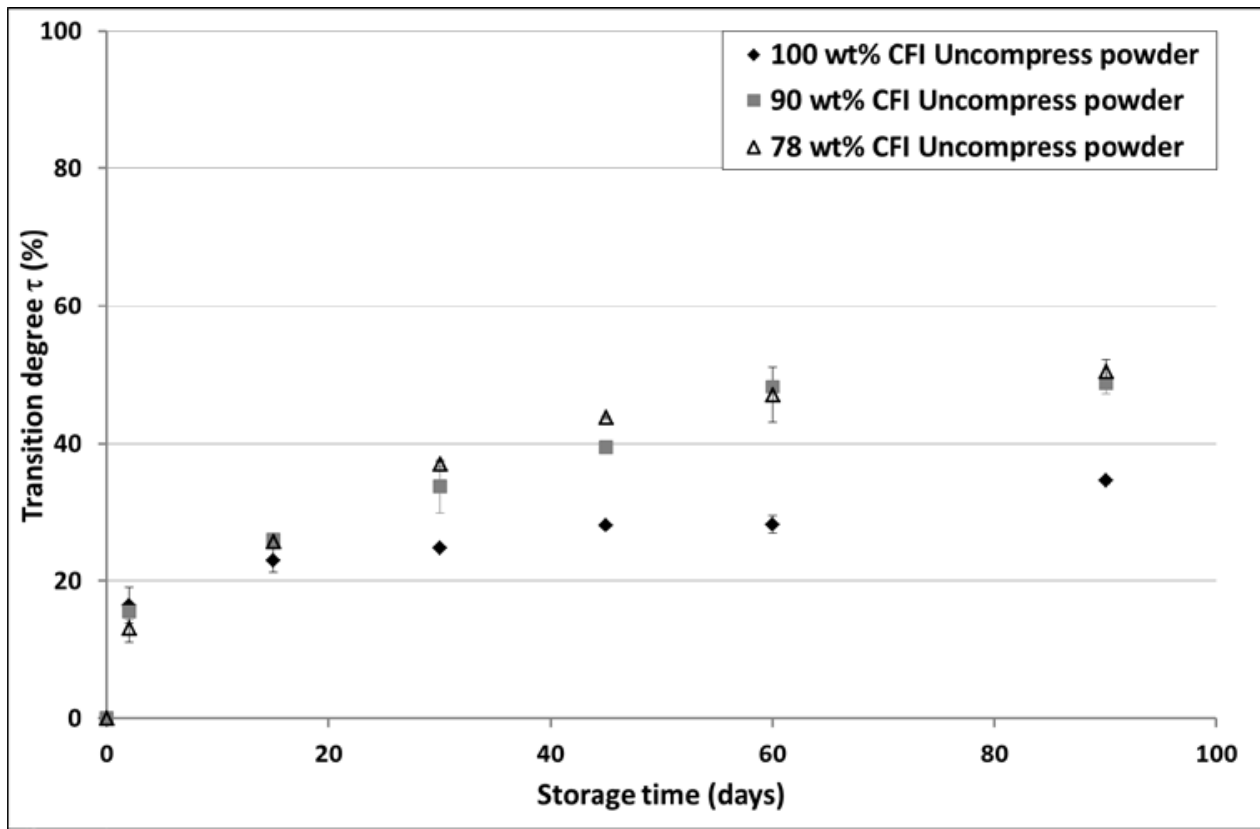

Fig.2: Evolution over time of the CFI transition degree in uncompressed powders for the three compositions studied, $n=3$.

\section{Evolution of the CFI transition degree $(\tau)$ in tablets \\ Impact of the velocity of the mobile punch during tableting}

175 As with uncompressed powders, a kinetic study of the CFI transition degree occurring in tablets was also conducted during three months. For each composition, results obtained for tablets were compared to the ones obtained in uncompressed powders. In a first step, the impact of compression load on CFI transition degree in tablets was conducted. Whatever the composition studied and the compression speed tested, no significant difference was observed between the three compression loads (data not shown). Consequently results obtained for tablets made at different compression pressures were gathered.

In order to evaluate the impact of the velocity of the mobile punch, the evolution over time of the CFI transition degree in tablet made at three different compression speeds $\left(50,500\right.$ and $\left.4500 \mathrm{~mm} \cdot \mathrm{min}^{-1}\right)$ was measured. For clarity reasons, Fig.3 presents the kinetic study of the CFI transition degree for one composition (100 wt\% of $\mathrm{CFI}$ ). However, the same results were observed for other compositions. Uncompressed powder and tablets made at three different compression speeds are represented by the cross and full symbols, respectively.

The transition profile in tablets was similar to the one observed with uncompressed powder: a first rapid growth stage until reaching a plateau. The plateau value was more important in tablets than in 
uncompressed powders. Moreover, for all compositions, a constant gap of around 25\% was observed between uncompressed powders and tablets. Whatever the compression speed, the transition degree was almost identical just after compression and the transition profiles were similar all along these kinetic studies. The velocity of the mobile punch did not alter the transition of the caffeine form I into form II after compression. Nevertheless, the content of the transformed phase (caffeine form II) was initially more important in tablets than in uncompressed powder.

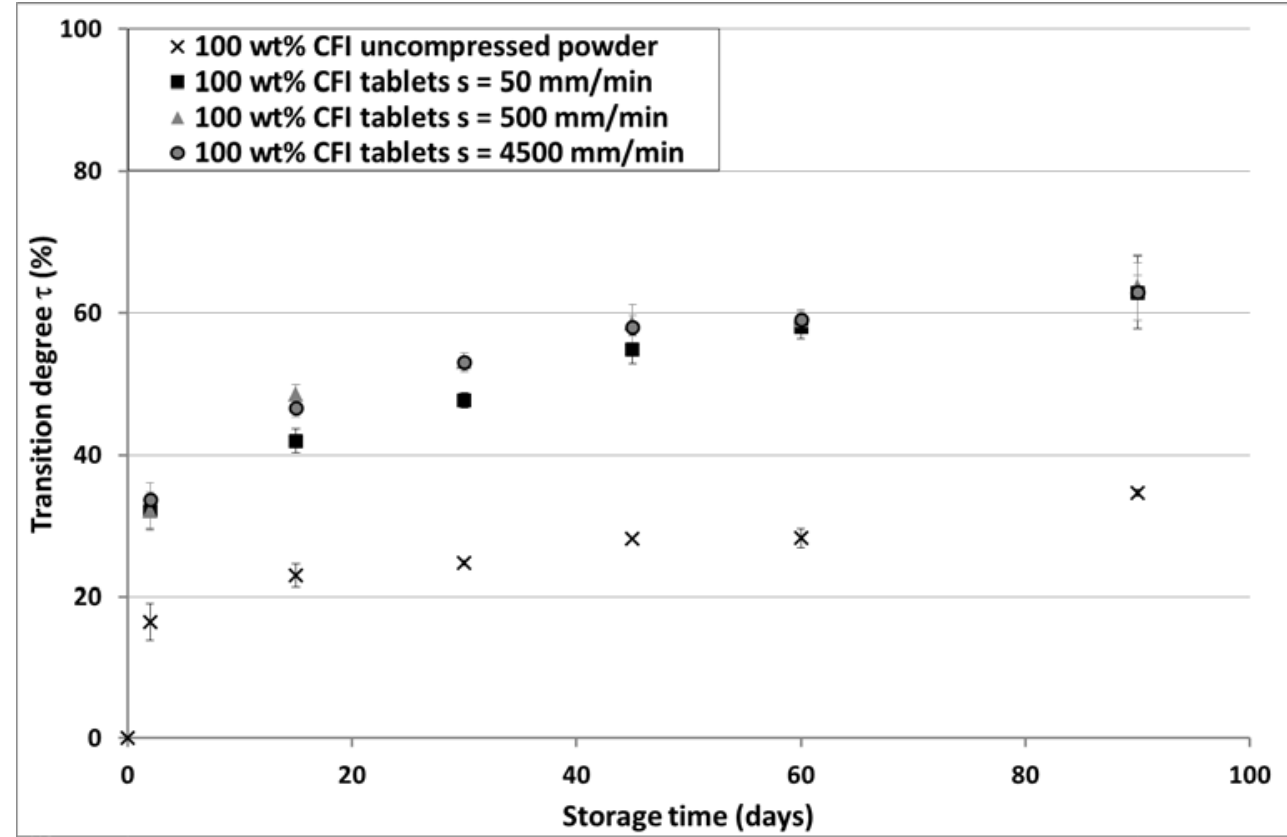

Fig.3: Evolution over time of the CFI transition degree in uncompressed powders and tablets of pure CFI made at three different compression speeds, $n=3$ for uncompressed powder and $n=9$ for tablets.

\section{Impact of the API dilution}

In order to observe the influence of the API dilution on the transition of caffeine form I into form II, Fig.4 displays the evolution over time of the gap between the CFI transition degree obtained in uncompressed powders and in tablets for the three compositions studied. Each composition is represented by a symbol. Considering that compression pressure and compression speed have not an impact on the CFI transition degree, the results obtained for tablets made at different compression loads and speeds were regrouped ( $n=27$ and $n=3$ for tablets and uncompressed powders, respectively). Then, for each composition studied, 205 the difference between uncompressed powder and tablets, for the transition of the caffeine Form I into Form II, was calculated. This method allows ensuring a satisfactory comparison between the different compositions. Two situations were observed depending on the tablet formulation. Indeed, for pure CFI, 
the calculated gap slightly increased during the first 30 days (between $16 \%$ and $26 \%$ ) until reaching a plateau from the thirtieth days (around $30 \%$ ). By contrast, for binary mixtures of $\mathrm{CFI} / \mathrm{MCC}$, gap was kept constant (around $25 \%$ ) all along the kinetic study. The addition of a diluent in the formulation seems to have an impact on the CFI transition degree, but this impact appears to be independent of the diluent content.

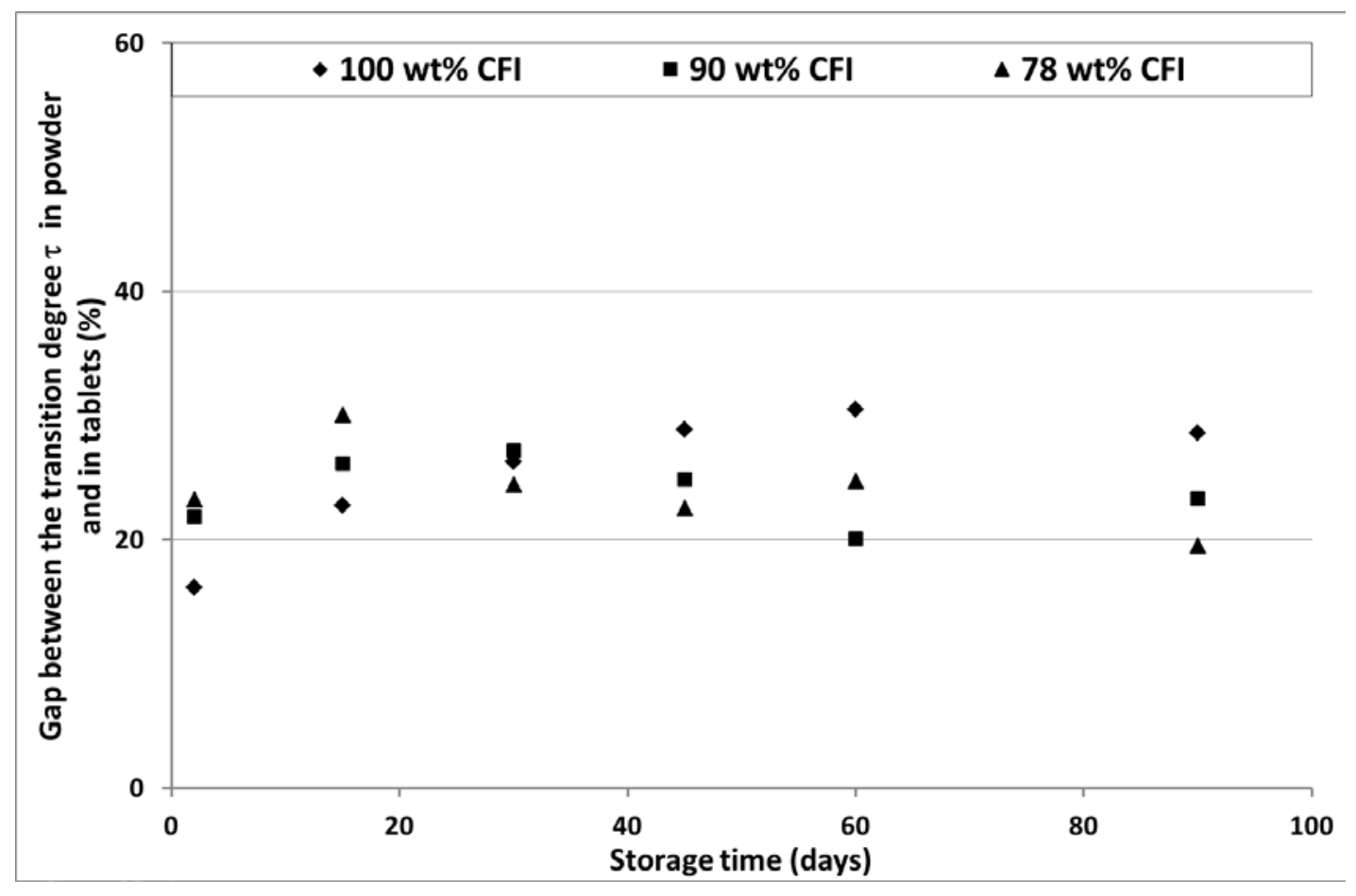

Fig.4: Evolution over time of the gap between the CFI transition degree in uncompressed powders and tablets for the three compositions studied.

\section{Discussion}

\section{Evolution of the CFI transition degree $(\tau)$ in uncompressed powders}

Whatever the composition studied the transition of the metastable caffeine Form I into its stable form 220 (Form II) was rapidly observed in uncompressed powders. These results are consistent with those find in the literature by Mazel et $a l .^{18}$, Hédoux et $a l_{.}{ }^{28}$ and Juban et $a l_{.^{4}}$ and confirm that the caffeine Form I which is metastable at room temperature and atmospheric pressure tends to move progressively with time towards its stable Form II. 


\section{Evolution of the CFI transition degree $(\tau)$ in tablets}

225 Several similarities were observed between results obtained in this study and the ones presented by Juban et $a I^{4}{ }^{4}$, even though the tableting presses were different. In fact, for all compositions, CFI transition degree was higher in tablets than in uncompressed powders. As reported by some authors in the literature ${ }^{18,20}$, these results mean that a part of this transformation was induced by the direct compression process. Moreover, the compression pressures did not have an impact on the transition of the metastable caffeine

230 Form I into its stable Form II. For CFI, whatever the intensity of the compression pressure applied, the transition degrees just after compression were similar. These results mean that the compression pressure has just a triggering effect when a sufficient compression pressure is applied during tableting. Moreover, the results show that the transition degree of the caffeine form I into form II just after compression was not dependent on the mobile punch velocity whatever the composition (pure caffeine or caffeine mixed with a diluent).. For this polymorphic system, the control of the punch velocity is unnecessary since a very small velocity (long compression time) and a high velocity (short compression time) led to the same transition degree. This process parameter seems to be inefficient for controlling polymorphic transition induced by the compression.

Fig.5 presents the evolution over time of the gap between the CFI transition degree obtained in uncompressed powders and in tablets for the three compositions studied. A comparison was made between results obtained in this work and the ones presented by Juban et al. ${ }^{4}$. Each composition was represented by a symbol. Full or empty symbols correspond to the gaps calculated in this study or the ones presented in the previous work, respectively. During the kinetic study of pure caffeine Form I, the calculated gap for the CFI transition degree between uncompressed powder and tablets displays a slight

245 increase during the first days before reaching a plateau. By contrast, the ones calculated for binary mixtures were kept constant all along the kinetic analysis (around 20\%). Results obtained for mixtures of $\mathrm{CFI} / \mathrm{MCC}$ are in agreement with the ones presented by Juban et $a l .^{4}$. No significant difference was observed between these gaps, meaning that the polymorphic transition of the caffeine Form I is no alter by process parameters applied during tablet manufacturing. Consequently, it could be interesting to express the results for the CFI transition degree in gap between uncompressed powder and tablets than in percentage of the transformed phase. This method allows comparing results obtained from different tableting processes. 


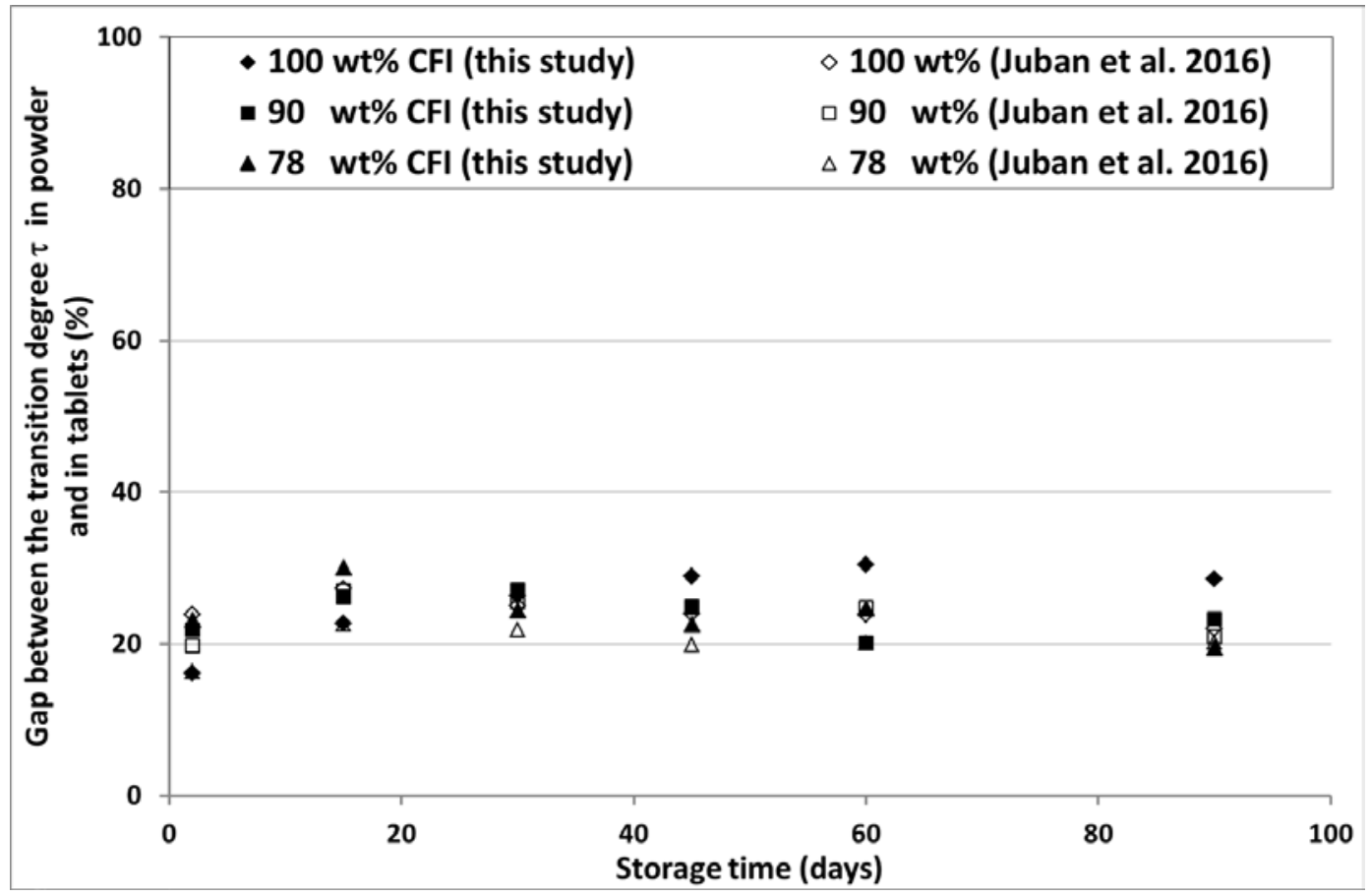

Fig.5: Evolution over time of the gap for CFI transition degree between uncompressed powders and tablets for the three compositions studied both in this work and results presented by Juban et $a$ l.

(2016)

\section{Analysis of the transformation kinetic rate and mechanism}

By using a stretched exponential law derived from the Johnson-Mehl-Avrami model, Juban et al. ${ }^{4}$ have shown that the solid-state transformation of caffeine was only controlled by nucleation of the Form II into the crystal lattice of the Form I. Since new data of transition was obtained on tablets manufactured with another type of press, one could wonder if the transition mechanism is similar or different. The same kinetic expression (Eq. 2) as previously used by Juban et al.4 was considered, and the two kinetic parameters were determined by fitting the model equation on the experimental data.

$265 X(t)=1-e^{\left[-\left(\frac{t}{\tau_{N}}\right)^{n}\right]}$

Where $t$ the time, $X$ the volume fraction of the transformed phase, $\tau_{N}$ the characteristic kinetic time, and $\mathrm{n}$ the exponent indicating the mechanism which controls the transition. A value of $\mathrm{n}$ lower than 1 means that the transition mechanism is only dependent on the nucleation. 
The calculated profiles are shown in Fig. 6 and compared with the experimental points. The fitted parameters $\mathrm{n}$ and $\tau_{\mathrm{N}}$ are displayed in Table 3. The mean relative deviation between the experimental and the calculated volume fractions is $5 \%$ both for uncompressed powders and tablets. These results confirm that the transition kinetic rate measured in this study could also be correctly represented with this stretched exponential law. The values of $\mathrm{n}$ are in a close range from 0.21 to 0.50 . This results are similar than the ones observed by Juban et al. ${ }^{4}$. Whatever the compression technology used, the transition 275 mechanism is nucleation dependent.

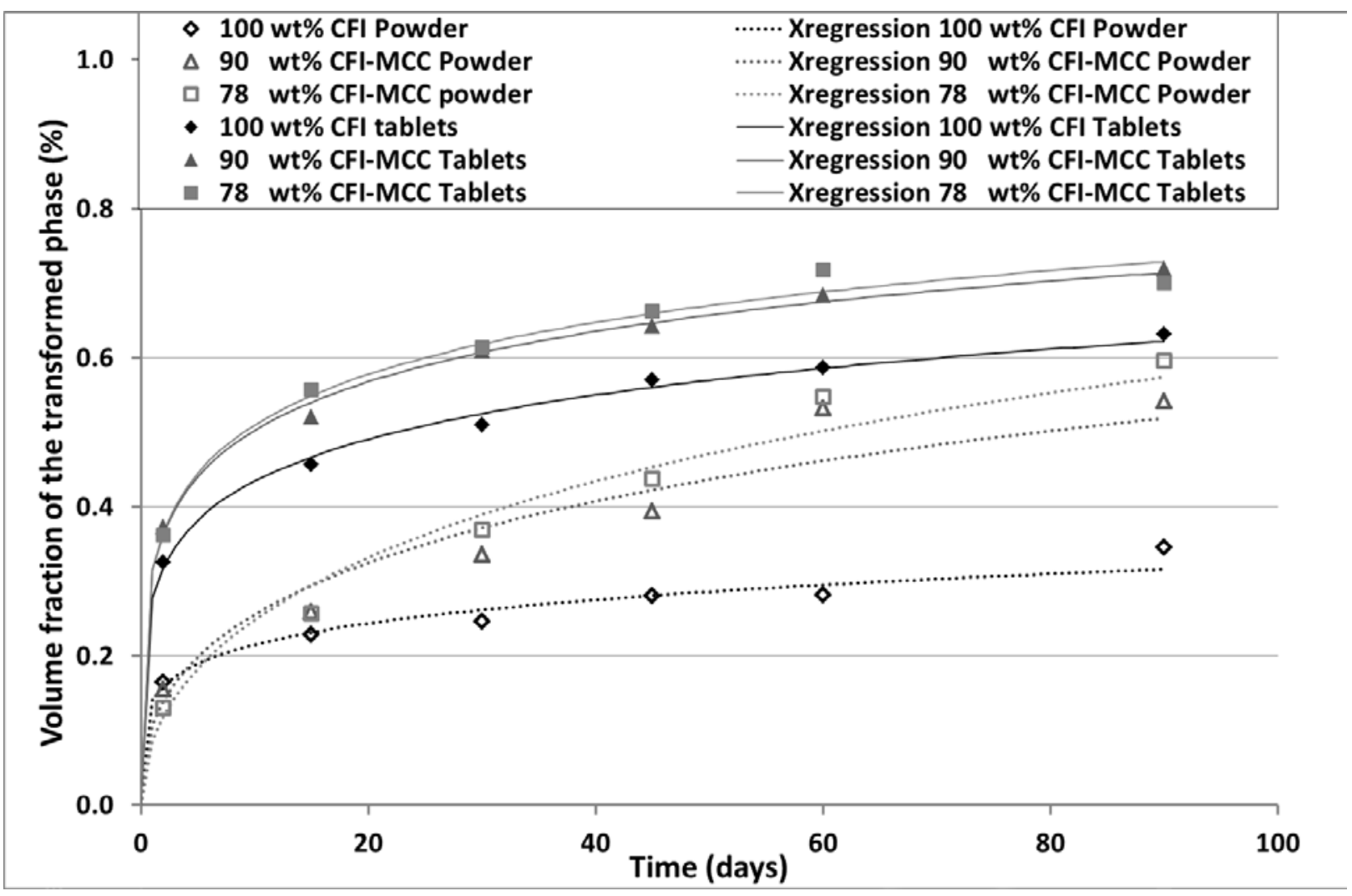

Fig.6: Evolution over time of the volume fraction of the transformed phase. Comparison between experimental data and calculated values obtained from the kinetic laws (2) for uncompressed powder and tablets, respectively. 
Table.3: Comparison of the values of $\tau_{N}$ and $\mathbf{n}$ calculated in this study with the kinetic laws (2) for uncompressed powder and tablets, respectively, with the ones presented by Juban et al., 2016.

\begin{tabular}{|c|c|c|c|c|c|c|c|c|c|}
\hline \multirow[b]{3}{*}{ Diluent } & \multirow[b]{3}{*}{ wt\% CFI } & \multicolumn{4}{|c|}{ This study } & \multicolumn{4}{|c|}{ Juban et $a l$. (2016) } \\
\hline & & \multicolumn{2}{|c|}{ Uncompressed powders } & \multicolumn{2}{|c|}{ Tablets } & \multicolumn{2}{|c|}{ Uncompressed powders } & \multicolumn{2}{|c|}{ Tablets } \\
\hline & & $\mathbf{n}$ & $\tau_{\mathrm{N}}$ & $\mathbf{n}$ & $\tau_{\mathrm{N}}$ & $\mathbf{n}$ & $\tau_{N}$ & $\mathbf{n}$ & $\tau_{N}$ \\
\hline- & 100 & 0.21 & 9994 & 0.24 & 101 & 0.33 & 114 & 0.19 & 8 \\
\hline \multirow{2}{*}{ MCC } & 90 & 0.41 & 191 & 0.27 & 39 & 0.30 & 147 & 0.25 & 13 \\
\hline & 78 & 0.50 & 124 & 0.28 & 34 & 0.20 & 398 & 0.19 & 23 \\
\hline
\end{tabular}

\section{Conclusion}

In order to improve the understanding of the PITs occurring during the direct compression process, a complementary study to a previous one (Juban et $a l .{ }^{4}$ ) was performed in order to investigate the impact of the velocity of the punch on the polymorphic transition since this process parameters is known to influence tablet mechanical properties. This was possible by using an electric press instead of a compression simulator.

Several similarities with the previous work were observed. The CFI transition degree was higher in tablet than in uncompressed powder, meaning that the direct tableting process has the ability to trigger the polymorphic transformation of the caffeine form I into form II. Moreover, the value of the CFI transition degree was not altered by the maximum compression load. In the same way, this study shows that the punch velocity had not a decisive influence on the level of the polymorphic transition of caffeine form I into form II just after compression. This observation is corroborated by the analysis of the mechanism of the transition occurring in the tablet at rest which is independent on the press technology used. Controlling the punch velocity seems not relevant for preventing or enhancing the transition of a solid form in a tabletting process

The incorporation of a diluent in the formulation had a small impact on the CFI transition degree. Nevertheless, unlike the results presented by Juban et $a{ }^{4}{ }^{4}$, the impact of the dilution of the caffeine Form I with MCC as diluent wasn't observed in this study. This difference could be due to the press compression technology used for tableting. 


\section{Acknowledgements}

The support of the Ministère de l'Enseignement Supérieur et de la Recherche is gratefully acknowledged. We would like to thank Medel'Pharm especially T. Ménard, G. Tardy and B. Villa as well as the technician

310 G. Conod-Nardi B. Ponsard and O. Pollet for their technical support. We also wish to thank the IVTV platform (ANR-10-EQPX-06-01).

\section{Declaration of interest}

The authors report no conflicts of interest. Only authors are responsible for the content and writing of 315 this paper.

\section{References}

1. Brittain HG. Effects of mechanical processing on phase composition. J. Pharm. Sci., 2002; 91, 15731580.

320 2. Zhang GGZ, Law D, Schmitt EA, Qiu Y. Phase transformation considerations during process development and manufacture of solid oral dosage forms. Adv. Drug Deliv., 2004; 56, 371-390.

3. Descamps M, Willart JF. Perspectives on the amorphization/milling relationship in pharmaceutical materials, Advanced Drug Delivery Reviews, 2016. Doi: 10.1016/j.addr.2016.01.011.

4. Juban A, Briançon S, Puel F. Processing-induced-transformations (PITs) during direct compression: Impact of tablet composition and compression load on phase transition of caffeine. Int. J. Pharm., 2016; $501,253-264$.

5. Bauer J, Spanton S, Henry R, Quick J, Dziki W, Porter W, Morris J. Ritonavir: an extraordinary example of conformational polymorphism. Pharmaceutical Res., 2001; 18, 859-866.

6. Morris KR, Griesser UJ, Eckhardt CJ, Stowell JG. Theoritical approaches to physical transformations of active pharmaceutical ingredients during manufacture processes. Adv. Drug Deliv. Rev., 2001; 48, 91114.

7. Petit $S$, Coquerel G. Transformations physiques de cristaux moléculaires induites par les procédés industriels de fabrication : approche théorique, conséquences et exemples. Cristal 3, 2004 ; conférence sur la cristallisation et la précipitation industrielles, Saint-Etienne. 
335 8. Wu CY, Seville JPK. A comparative study of compaction properties of binary and bilayer tablets. Powder Technol., 2009; 189, 285-294.

9. Hennigan MC, Ryder AG. Quantitative polymorph contaminant analysis in tablets using raman and near infra-red spectroscopies. J. Pharm. Biomed. Anal., 2013; 72, 163-171.

10.Zhang Y, Law Y, Chakrabarti S. Physical properties and compact analysis of commonly used direct compression binders. AAPS Pharm. Sci. Tech., 2003; 4, Article 62.

11.Chieng N, Rades T, Aaltonen J. An overview of recent studies on the analysis of pharmaceutical polymorphs. J. Pharm. Biomed. Anal., 2011; 55, 618-644.

12.Nauha E, Bernstein J. "Predicting" polymorphs of pharmaceuticals using hydrogen bond propensities: probenecid and its two single-crystal-to-single phase transitions. J. Pharm. Sci., 2015; 104, 2056-2061.

13.Chakravarty P, Suryanarayanan R, Govindarajan R. Phase transformation in thiamine hydrochloride tablets: influence on tablet microstructure, physical properties, and performance. J. Pharm. Sci., 2012; $101,1410-1422$.

14.Chan HK, Doelker E. Polymorphic transformation of some drugs under compression, Drug Development and Industrial Pharmacy., 1985; 11, 315-332.

350 15.Lefebvre C, Guyot-Hermann AM, Draguet-Brughmans M, Bouche R, Guyot JC. Polymorphic transitions of carbamazepine under grinding and compression. Drug Development and Industrial Pharmacy., 1986; $12,1913-1927$.

16.Boldyreva EV, Dmitriev V, Hancock BC. Effect of pressure up to $5.5 \mathrm{GPa}$ on dry powder samples of chlorpropamide form-A. Int. J. Pharm., 2006; 327, 51-57.

355 17.Otsuka M, Ibe K, Tokudome Y, Ohshima H. Nano- and macro- geometrical structural change of caffeine and theophylline anhydrate tablets during hydration process by using X-ray computed tomography. Colloids and Surfaces B: Biointerfaces, 2009 ; 73, 351-359.

18. Mazel V, Delplace C, Busignies V, Faivre V, Tchoreloff P, Yagoubi N. Polymorphic transformation of anhydrous caffeine under compression and grinding: a re-evaluation. Drug. Dev. Ind. Pharm., 2011; 37, 832-840.

19.Pinto SS, Diogo P. Thermochemical study of two anhydrous polymorphs of caffeine. J. Chem. Thermodyn.; 2006; 38, 1515-1522.

20.Pirttimakki J, Laine E, Ketolainen J, Paronen P. Effects of grinding and compression on crystal structure of anhydrous caffeine. Int. J. Pharm., 1993; 95, 93-99. 
21. Hubert S, Briancon S, Hédoux A, Guinet Y, Paccou L, Fessi H, Puel F. Process induced transformations during tablet manufacturing: phase transition analysis of caffeine using DSC and low frequency microRaman spectroscopy. Int. J. Pharm., 2011; 420, 76-83.

22. Hédoux A, Guinet Y, Paccou L, Danède F, Derollez P. Polymorphic transformation of anhydrous caffeine upon grinding and hydrostatic pressuring analyzed by low-frequency raman spectroscopy. J. Pharm. Sci., 2013; 102, 162-170.

23.Garr JSM, Rubinstein MH. An investigation into the capping of paracetamol at increasing speeds of compression. Int. J. Pharm., 1991a; 72, 117-122.

24.Garr JSM, Rubinstein MH. The effect of rate of force application on the properties of microcrystalline cellulose and dibasic calcium phosphate mixtures. Int. J. Pharm., 1991b ; 73, 75-80.

375 25.Larhrib H, Wells Jl, Rubinstein $\mathrm{MH}$. Compressing polyethylene glycols: the effect of compression pressure and speed. Int. J. Pharm., 1997; 147, 199-205.

26. Tye CK, Sun CC, Amidon GE. Evaluation of the effects of tabletting speed on the relationships between compaction pressure, tablet tensile strength, and tablet solid fraction. J. Pharm. Sci., 2004; 94, 465-472.

27.European Pharmacopoeia, 2014. European Directorate for the Quality of Medicines \& HealthCare (EDQM), eighth ed., Strasbourg, France.

28. Hédoux A, Decroix AA, Guinet Y, Paccou L, Derollez P, Descamps M. Low- and High-Frequency Raman Investigations on Caffeine: Polymorphism, Disorder and Phase Transformation. J. Phys. Chem. B., 2011; 115, 5746-5753. 